\title{
Family feud: permanent group splitting in a highly philopatric mammal, the killer whale (Orcinus orca)
}

\author{
Eva H. Stredulinsky ${ }^{1,2} \cdot$ Chris T. Darimont ${ }^{1,3,4} \cdot$ Lance Barrett-Lennard $^{5,6} \cdot$ Graeme M. Ellis $^{2} \cdot$ John K. B. Ford ${ }^{2,6}$
}

Received: 3 March 2020 / Revised: 30 January 2021 / Accepted: 3 February 2021 / Published online: 18 February 2021

(C) Crown 2021

\begin{abstract}
For animals that tend to remain with their natal group rather than individually disperse, group sizes may become too large to benefit individual fitness. In such cases, group splitting (or fission) allows philopatric animals to form more optimal group sizes without sacrificing all familiar social relationships. Although permanent group splitting is observed in many mammals, it occurs relatively infrequently. Here, we use combined generalized modeling and machine learning approaches to provide a comprehensive examination of group splitting in a population of killer whales (Orcinus orca) that occurred over three decades. Fission occurred both along and across maternal lines, where animals dispersed in parallel with their closest maternal kin. Group splitting was more common: (1) in larger natal groups, (2) when the common maternal ancestor was no longer alive, and (3) among groups with greater substructuring. The death of a matriarch did not appear to immediately trigger splitting. Our data suggest intragroup competition for food, leadership experience and kinship are important factors that influence group splitting in this population. Our approach provides a foundation for future studies to examine the dynamics and consequences of matrilineal fission in killer whales and other taxa.
\end{abstract}

\section{Significance statement}

Group living among mammals often involves long-term social affiliation, strengthened by kinship and cooperative behaviours. As such, changes in group membership may have significant consequences for individuals' fitness and a population's genetic structure. Permanent group splitting is a complex and relatively rare phenomenon that has yet to be examined in detail in killer whales. In the context of a growing population, in which offspring of both sexes remain with their mothers for life, we provide the first in-depth examination of group splitting in killer whales, where splitting occurs both along and across maternal lines. We also undertake the first comprehensive assessment of how killer whale intragroup cohesion is influenced by both external and internal factors, including group structure, population and group demography, and resource abundance.

Communicated by J. Mann

Eva H. Stredulinsky

eva.stredulinsky@dfo-mpo.gc.ca

1 Department of Geography, University of Victoria, P.O. Box 1700 STN CSC, Victoria, BC V8W 2Y2, Canada

2 Pacific Biological Station, Fisheries and Oceans Canada, 3190 Hammond Bay Road, Nanaimo, BC V9T 6N7, Canada

3 Raincoast Conservation Foundation, P.O. Box 2429, Sidney, BC V8L 3Y3, Canada

4 Hakai Institute, P.O. Box 309, Heriot Bay, BC V0P 1H0, Canada

5 Coastal Ocean Research Institute, Ocean Wise, P.O. Box 3232, Vancouver, BC V6B 3X8, Canada

6 Department of Zoology, University of British Columbia, \#4200 6270 University Blvd, Vancouver, BC V6T 1Z4, Canada
Keywords Group splitting · Matrilineal fission · Food competition · Kinship · Philopatry $\cdot$ Killer whale

\section{Introduction}

A matrilineal society is a stable social strategy adopted by many gregarious mammals, revolving around cooperative groups of related females. Most matrilineal societies exhibit sex-biased dispersal; commonly, females are philopatric (remaining in their natal geographic range and/or social group) and males disperse, often around the age of sexual maturity (Greenwood 1980; Johnson 1986; Clutton-Brock and Lukas 2012). Under unfavourable group conditions, often associated with a group's growing size or changing composition, group fission is the primary process by which philopatric females may disperse (e.g. Dittus 1988; Henzi et al. 1997; Holekamp 
et al. 1997; Lefebvre et al. 2003; Van Horn et al. 2007). Group fission in matrilineal societies often occurs along lines of maternal relatedness, allowing animals to maintain important, familial relationships while optimizing group size (ChepkoSade and Olivier 1979; Archie et al. 2006; Widdig et al. 2006; VanderWaal et al. 2009; Sueur et al. 2011). Group splitting, particularly when kin-biased, may have significant influence on individual fitness (Armitage 1987; Dittus 1988; Pollack and Rubenstein 2015) and population genetic structure (Chepko-Sade and Sade 1979; Melnick and Kidd 1983; Widdig et al. 2006).

Although all documented killer whale (Orcinus orca) societies are matrilineal, they exhibit varying degrees of natal social philopatry (fidelity to the family group into which they were born). Among social mammals, fish-eating 'resident' killer whales of the eastern North Pacific represent a rare case of extreme bisexual social philopatry, where both sexes remain with their natal group throughout life and individual dispersal is exceedingly rare (Matkin et al. 1999a; Ford et al. 2000). Because of this unusual social strategy, resident killer whales live in highly stable matrilineal groups composed of a female, her offspring and up to five generations of her descendants through maternal lines (Bigg et al. 1990). Because group size is not moderated by individual dispersal, matrilineal splitting provides the only means by which new groups may form in resident killer whale society.

Resident killer whales in coastal waters of the eastern North Pacific occur in three discrete populations that are socially and genetically isolated from one another, despite having overlapping geographic ranges (Bigg et al. 1990; Barrett-Lennard 2000; Ford et al. 2000; Matkin et al. 2007). The genealogy and social organization of these populations are described through several long-term studies that use photoidentification of individually distinct natural markings to conduct annual censuses of individuals (Bigg 1982; Matkin et al. 1999b; Ford et al. 2000; Center for Whale Research 2016; Towers et al. 2020). Our study focuses on the northern resident killer whale (NRKW) population, which has been studied since 1973 and ranges from Washington State to southeastern Alaska (USA). This population has grown steadily since the beginning of its study and was composed of 289 animals in 2014 (Fig. 1a; DFO 2019; Towers et al. 2020).

Early in the study of resident killer whales, it was discovered that individuals lived in highly stable social groups that were termed 'pods'. Although it was initially thought that pods were permanent (Bigg et al. 1976) or long-term breeding units (Bigg 1982), it was soon recognized that pods were composed of one to several 'maternal groups' (Bigg et al. 1987), 'matrilineal groups' (Bigg et al. 1990) or 'matrilines' (Ford et al. 2000; Towers et al. 2020), terminology we use here with revision (Table 1).

During the first decade of study, pods were socially cohesive, and the maternal groups within them associated more
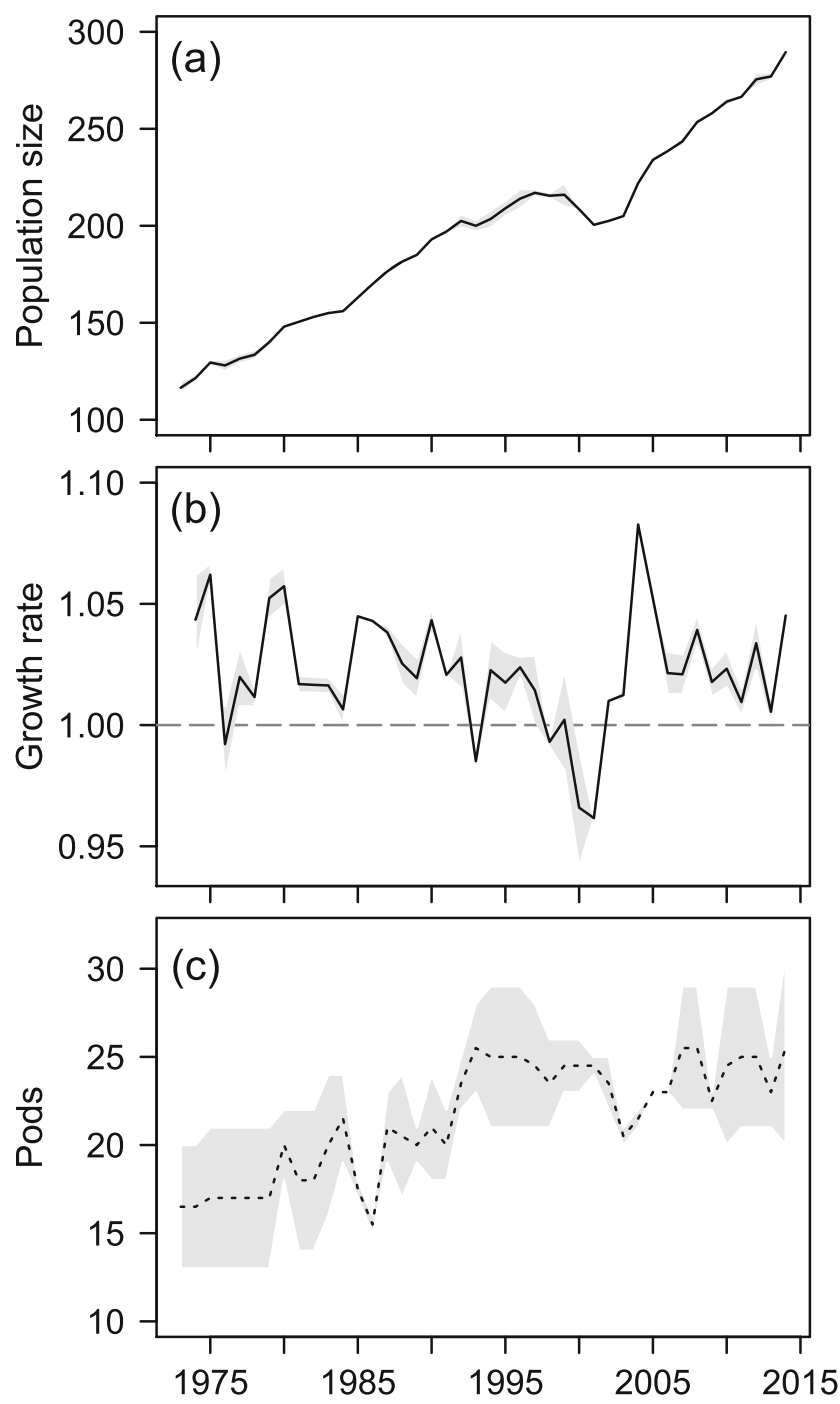

Fig. 1 Northern resident killer whale a population size and $\mathbf{b}$ population annual growth rate, and $\mathbf{c}$ the estimated number of pods present in the population. Grey shading denotes minimum and maximum values of estimates

regularly with one another than with maternal groups from different pods (Bigg et al. 1990). In the mid-1980s, researchers first observed maternal groups within pods associating less frequently with one another, with some disassociating from one another completely. Of the 16 pods originally identified by Bigg et al. (1990), only half met the definition of a pod by the year 2000 (Ford and Ellis 2002).

Splitting was observed within pods originally composed of both multiple and single maternal groups. In the former case, it was assumed that the various maternal groups originated from a now-deceased, common maternal ancestor (i.e. were of the same matriline; Ford 1989, 1991; Barrett-Lennard 2000; Ford et al. 2000; Deecke et al. 2010). In the latter, the matriarch of the pod was alive at the beginning of the study but, upon her death, her lineage gave rise to several maternal groups that subsequently became socially separated (Fig. 2a). This 
Table 1 Resident killer whale social organization terminology. Social grouping terms are hierarchical and have been established over the course of the NRKW study. Group substructures are matrilineal units that we use to describe social group structure (see Supplementary Materials Fig. 1). A matriline denotes all individuals descended from a common maternal ancestor. Direct maternal ancestor(s) refer to individuals from whom one descends in a direct line through mothers (i.e. mother, maternal grandmother, maternal grandmother's mother, etc.). Direct maternal descendants refer to a female's offspring and all offspring of her female descendants (e.g. daughter's offspring, granddaughter's offspring, etc.)

\begin{tabular}{|c|c|}
\hline Term & Definition \\
\hline \multicolumn{2}{|l|}{ Social groupings } \\
\hline Population & $\begin{array}{l}\text { A community of one or more clans that associate with one another. May be sympatric with } \\
\text { but does not mix socially with other populations. (Bigg et al. 1990) }\end{array}$ \\
\hline Clan & $\begin{array}{l}\text { Maternal groups with vocal dialects that include shared call types }{ }^{1} \text {. Different clans are } \\
\text { acoustically distinct and may represent separate matrilines. (Ford 1991) }\end{array}$ \\
\hline Pod & $\begin{array}{l}\text { An assemblage of maternal groups that, on average, spend more than } 50 \% \text { of their time } \\
\text { together }^{2} \text { (Bigg et al. 1990). Pods are composed of one or more maternal groups. } \\
\text { Maternal groups found in the same pod likely share a common maternal ancestor } \\
\text { (i.e. belong to the same matriline) })^{3}\end{array}$ \\
\hline Maternal group & $\begin{array}{l}\text { Individuals }{ }^{4} \text { descended from a common direct maternal ancestor (matriarch) that always } \\
\text { travel together (Bigg et al. 1990). Maternal groups are named after the most recent ma- } \\
\text { triarch of the group and are the core social unit of resident killer whales }\end{array}$ \\
\hline \multicolumn{2}{|c|}{ Group substructures } \\
\hline $\begin{array}{l}\text { Complete unit } \\
\text { (CU) }\end{array}$ & $\begin{array}{l}\text { A living female with no living direct maternal ancestors in the social group, and her direct } \\
\text { maternal descendants }\end{array}$ \\
\hline $\begin{array}{l}\text { Nested unit } \\
\text { (NU) }\end{array}$ & $\begin{array}{l}\text { A living female and her direct maternal descendants, nested within a CU (i.e. the female is } \\
\text { socially cohesive with at least one direct maternal ancestor). Once socially independent } \\
\text { from the rest of its } \mathrm{CU} \text {, the NU is considered its own CU }\end{array}$ \\
\hline Subunit & $\begin{array}{l}\text { The largest matrilineal substructure in the group, the most likely subset of the group to } \\
\text { socially disperse. For groups without a living matriarch, this refers to the largest CU in the } \\
\text { group. For groups with a living matriarch, this refers to the largest NU in the group }\end{array}$ \\
\hline Basal unit (BU) & $\begin{array}{l}\text { Mother-offspring group composed of a female, her sons, and her daughters without } \\
\text { offspring. Any females with offspring of their own are considered a separate BU, } \\
\text { excluded from their mother's BU. Unlike CUs and NUs, this unit does not require a living } \\
\text { mother }\end{array}$ \\
\hline
\end{tabular}

${ }^{1}$ Call repertoires of clans can persist for at least 60 years and likely longer (JKBF 1991, unpubl. data)

${ }^{2}$ Association index selection depends on the bias of a given study's sampling process and therefore one's quantitative delineation of 'pod' may not be equivalent to a simple ratio index (SRI) of $>0.5$ (or this study's definition, using HWI > 0.6)

${ }^{3}$ A pod gives rise to further pods when group splitting occurs. For example, a pod is composed of a living matriarch with three daughters, all with descendants of their own. Upon the death of the matriarch, the three daughters and their direct maternal descendants are still considered one pod. When the three daughters become socially independent of one another, three new pods arise - each led by a daughter of the deceased matriarch. Additionally, when a daughter separates from her mother, her nested unit becomes a pod of its own

${ }^{4}$ Maternal groups can include individuals without a living, direct maternal ancestor. These individuals are therefore external to the complete and nested unit terms defined here, as these terms refer to groups requiring a living female and her direct maternal descendants. These individuals are, however, included in a basal unit, which does not require a living mother process of fission along extant maternal lines is the most common form of matrilineal fission and lineage creation (e.g. Furuya 1968, 1969; Nash 1976; Chepko-Sade and Sade 1979; Oi 1988; Ménard and Vallet 1993; Lefebvre et al. 2003; Archie et al. 2006; Widdig et al. 2006).

In the late 1990s, a second form of group splitting was observed in the NRKW population, where a female (along with her direct maternal descendants) would fission with her pod while her mother was still alive (Fig. 2b). This process of fission across extant maternal lines was quite unexpected because, until that time, all animals in resident populations were known to stay with their mother for their entire lives. We distinguish these two forms of group fission by the absence and presence of a matriarch, respectively, where the 'matriarch' is considered the oldest extant direct maternal ancestor shared by all individuals in the group.

Whether group splitting in resident killer whales is a mutual or unilateral process and whether it results in locational dispersal is unknown. Therefore here, we use the terms 'social dispersal', 'splitting (from)', or 'separating (from)' broadly, not to suggest directionality within these events, but to simply denote the social partitioning of one's group from the perspective of the given focal animal(s).

Whereas individual social dispersal patterns have been described previously in killer whale populations (e.g. Baird and Whitehead 2000), observations of group splitting have been 


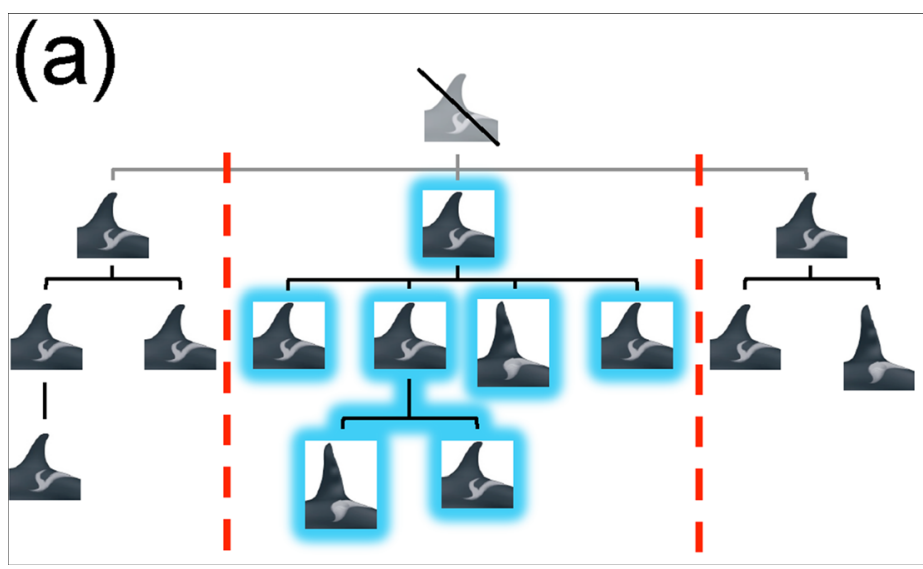

Fig. 2 Matrilineal fission was exhibited in two ways in the northern resident killer whale population. a A subunit separates from maternal relatives with which there is no longer a living common maternal ancestor (matriarch). The largest complete unit (CU) present in the pod is considered the subunit for this type of splitting. In this example, where a

noted only anecdotally (e.g. Scheel et al. 2001; Esteban et al. 2015) and not described in detail. Our study provides an indepth description and quantification of group splitting in the NRKW population, examining the duration of the splitting process, the longevity of splits, the frequency of splitting and whether splitting in the presence or absence of a matriarch differ in those respects. We also relate NRKW population dynamics to splitting and group structure.

In addition to describing matrilineal fission in the NRKW population, we also address concerns that environmental factors could be driving these fission events. Group splitting in the NRKW population was anecdotally observed to coincide with years of low abundance of Chinook salmon (Oncorhynchus tshawytscha), their preferred prey (Ford et al. 1998; Ford and Ellis 2006). Thus, there are concerns that salmon abundance, which is impacted by fisheries and other human disturbance, may be affecting the integrity of NRKW social organization.

We hypothesize that population growth drives group splitting in the NRKW, with groups splitting when they grow to exceed some threshold size. However, of greater ecological interest are the underlying causes of group splitting in NRKWs. Accordingly, we aim to identify factors that make large group sizes unfavourable in this population. We consider four hypotheses to explain the mechanism of NRKW group splitting, recognizing that any number of these processes could be occurring concurrently and are not necessarily independent of one another:

(1) Food competition: Reduced per capita prey availability increases intragroup competition for food resources, thus promoting fission to reduce competition. We predict that

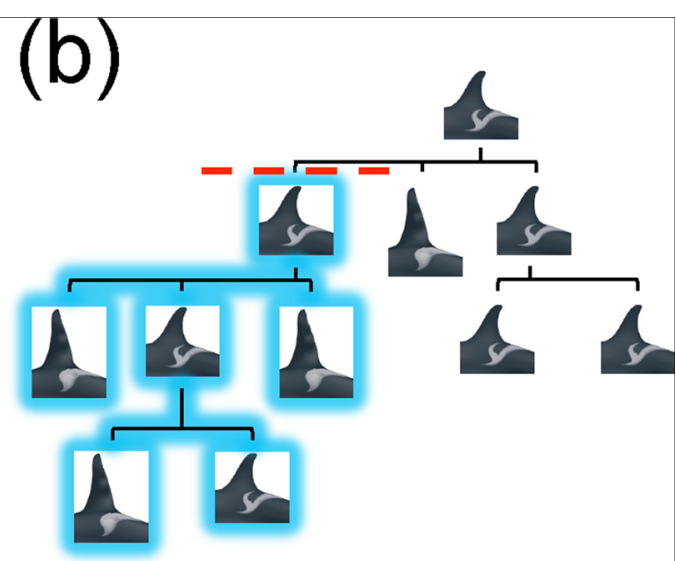

group is composed of more than two CUs, all CUs may simultaneously split apart or the remaining CUs may remain together after separating from the subunit. b A subunit separates from a living maternal ancestor and the largest nested unit (NU) present in the pod is considered the subunit. Subunits for these theoretical groups are highlighted in blue fission is more likely during years of low salmon abundance than during years of high salmon abundance, and more likely in groups with greater caloric requirements than in those with fewer caloric requirements.

(2) Kinship: Relatedness drives kin-directed behaviours that promote philopatry (e.g. food sharing). We predict that fission is promoted when a group's average maternal relatedness decreases, to reduce intragroup competition and optimize potential inclusive fitness benefits of within-group cooperation.

(3) Reproductive conflict: Calving synchrony increases intragroup competition for food resources through increased metabolic costs due to lactation. Here, we consider calving synchronous when multiple local females birthed calves within such a time interval that their estimated lactation periods overlapped. We predict that fission is promoted in groups with simultaneously lactating females, to mitigate costs of reproductive conflict.

(4) Leadership experience: The capability of a female to lead her group and ensure its survival and reproductive success hinges on her accumulated social and ecological knowledge. We predict that fission is inhibited until a group contains at least two females with sufficient experience to lead their respective groups, where fission is more likely in groups with older non-matriarch females than in groups with younger non-matriarch females.

We use a combined generalized modeling and machine learning approach to explore these hypotheses, giving consideration to extrinsic and intrinsic factors considered likely to affect intragroup cohesion in the NRKW population. 


\section{Methods}

\section{Assessing intrapod cohesion}

Data were derived from a long-term photo-identification study of NRKWs off the coast of British Columbia (BC), Canada, where individuals were identified by dorsal fin features and distinct natural markings on their 'saddle patch', the lightly pigmented area posterior to the dorsal fin (Bigg 1982). Our data consisted of records of boat-based encounters $(n=4667)$ with photographically or visually identified NRKW from 1973 to 2014. An 'encounter' entails documentation of identified individuals exhibiting coordinated group behaviour (e.g. behavioural state, direction of travel) within a geographic area that allows animals to be in acoustic communication with one another. All individuals present within an encounter were considered associated. As this study involved focal animals in the field, blind data recording was not possible. We restricted our analysis to encounters occurring between June and October to reduce potential seasonal influence and ensure comparable survey effort among years.

As individual dispersal in resident killer whale populations is exceptionally rare, we considered male offspring, and female offspring without surviving offspring of their own, representatives of their mother to generate functional units ('basal units', BUs; Table 1, Supplementary Materials Fig. 1) by which to assess intrapod cohesion. We approximated intrapod cohesion using the Half Weight Index association measure (HWI; Cairns and Schwager 1987):

$H W I=\frac{\text { successes }}{N}=\frac{\text { successes }}{\text { successes }+\frac{1}{2}(\text { failures })}$

where 'successes' were encounters wherein all basal units of a given pod were present (i.e. at least one member of each basal unit was accounted for). 'Failures' were any encounters in which at least one basal unit within the pod was present and at least one basal unit within the pod was absent. We considered a pod to be socially cohesive if it exhibited strong intragroup association (HWI > 0.6) in the given year. To ensure a minimum threshold of precision, we required that each estimate of intrapod cohesion be derived from a minimum of five unique encounters in the given year to be included in our analyses (Whitehead 2008). On average, groups adequately sampled were encountered 25 times (median $=11$, interquartile range, $I Q R=22$ ) in a given year (Supplementary Materials Table 1).

\section{Introducing new pods}

Fission events (splits) occurred when a previously cohesive pod was not cohesive in the given year, and fusion events (reunions) occurred when a previously split pod was cohesive in the given year (Supplementary Materials Table 1). The membership of new pods was defined according to the association strength among its basal units. This differs from practice in the NRKW study, where the original pod designations as defined by Bigg et al. (1990) continue to be used as fixed delineations of the population. For ease of reference hereafter, we use the term 'legacy pods' to refer to the 16 original pods defined by Bigg et al. (1990).

The number of pods present in the population in each year of the study was estimated taking into account uncertainty in the timing of fission and fusion events due to limitations of sampling. In a given year, inadequately sampled pods that were deemed cohesive in the last year they were adequately sampled $(y l s)$ and in the next year they were adequately sampled (yns) were assumed cohesive. Minimum pod counts were obtained by assuming that all inadequately sampled pods whose state of cohesion was at odds in $y l s$ and $y n s$ (i.e. fission or fusion event occurred sometime between $y l s$ and $y n s$ ), as well as those with no $y l s$ or $y n s$ due to the start or end of the study, respectively, were cohesive. Conversely, maximum pod counts were calculated by assuming the aforementioned pods were not cohesive. The number of pods resulting from groups assumed to be incohesive were defined according to the delineation among basal units observed in the incohesive $y l s$ or $y n s$. For pods assumed incohesive without $y l s$ or $y n s$, the number of resultant pods was derived from the number of 'complete units' (CUs) present in the group (Table 1; Supplementary Materials Fig. 1). Our 'best' estimate of pods present in the population was derived from the mean of our minimum and maximum estimates each year.

\section{Population dynamics, pod structure and fission}

To investigate potential effects of population dynamics on NRKW social organization, we examined the relationship between NRKW population growth, rates of group fission and fusion, and pod structure (Supplementary Materials Table 1). We examined the effect of population growth using KruskalWallis rank sum testing, comparing net changes in the number of pods and the frequency of matrilineal fission and fusion among three distinct periods of NRKW population growth: (1) 1973-1994, a period of unrestrained growth $(\lambda=$ $2.75 \%$ ); (2) 1995-2003, when the population experienced high rates of mortality and no net growth $(\lambda=-0.04 \%)$; and (3) 2004-2014, another period of steady, significant growth $(\lambda=3.19 \%)$ (Fig. 1b, c). We also assessed the relationship between population size and the structure of pods using Pearson correlation tests. Pod characteristics that we examined included the number of pods in the population, the mean number of CUs per pod, the mean number of individuals per $\mathrm{CU}$ and the mean number of individuals per pod. 


\section{Longevity of fission}

To assess the permanence of group fission events, we estimated the probability that a once-cohesive pod would reform following a fission event. We used Kaplan-Meier non-parametric survival analysis (Kaplan and Meier 1958) to estimate the time-sensitive probability of a group remaining apart after fission, using the number of years since a pod had split and whether or not it was a socially cohesive group in the given year. Pods that had not reunited by the end of our time series were considered right-censored. Additionally, we examined the probabilistic timing of reunion events $(n=53)$ using event-only Kaplan-Meier survival analysis. Survival analysis was conducted using the survfit function in the R package 'survival' (Therneau 2014).

\section{Determinants of group fission}

\section{Explanatory variables}

We selected 12 demographic, genealogical, energetic and environmental measures that were biologically relevant to our four hypotheses to analyse in the context of intrapod cohesion. We assessed these measures at various levels of NRKW social organization, resulting in 21 explanatory variables sampled in each year of our time series.

We assessed seven group demographic measures: counts of individuals and CUs within pods, mean size of CUs within pods, presence of a matriarch, proportions of reproductive females, lactating females and physically mature males within pods, and the age structure within pods (Supplementary Materials Table 2). We derived these measures from annual censuses of the NRKW population, which detail the condition, age and reproductive status of each animal in each year. These data are held in a registry maintained since 1973 by the Cetacean Research Program, Pacific Biological Station (Bigg et al. 1990; Ford et al. 2000; Olesiuk et al. 2005; DFO CRP 2015). We assessed the seven demographic measures at the pod level and some at the level of the subunit and population, resulting in 14 demographic variables. The 'subunit' refers to the largest matrilineal substructure in the pod, considered the most likely subset of the group to socially disperse. As the largest substructure of the pod, the subunit would likely have the greatest caloric needs and the weakest bonds to individuals outside of the subunit (due to lower average relatedness). Also, it would tend to be led by an older (and thereby more experienced) female and have greater leadership capacity in general (due to higher median age). For pods without a living matriarch, this is the largest $\mathrm{CU}$ in the group and, for pods with a living matriarch, this is the largest 'nested unit' (NU) in the group (Fig. 2; Table 1; Supplementary Materials Fig. 1). We refer to the matriarch of the subunit as the 'submatriarch'.
To assess intrapod maternal relatedness, we estimated the pairwise coefficient of maternal relatedness (assuming a noninbreeding population) among all individuals within each pod. Matrilineal kinship in NRKWs is inferred by tracing individuals from birth and observing close, long-term associations between females and young animals (Ford et al. 2000; Towers et al. 2020). Our estimates of intrapod maternal relatedness account for known maternal relationships (observed since birth), as well as relationships among animals born before the study whose maternal lineages have been inferred from consistent behavioural observations. These associationbased maternal assignments have been genetically validated (Barrett-Lennard 2000). We derived two variables from our genealogically based measure of maternal relatedness. First, we estimated the average pairwise coefficient of maternal relatedness among all individuals within each pod $(\mathrm{Rg})$. Second, we estimated the average degree of maternal relatedness between the submatriarch and her direct descendants (Rsm), relative to that between her and the rest of her pod (i.e. her mother and her non-descendant relatives; Rng). We refer to this second measure of maternal relatedness as 'relative submatriarch relatedness' (Rxm; Supplementary Materials Fig. 2). As Rng could not always be calculated (i.e. when the most recent common maternal ancestor was unknown), we used $\mathrm{R} g$ as a proxy for Rng in all cases to estimate $\mathrm{R} x m$. We deemed $\mathrm{R} g$ an appropriate substitute for Rng, as the two measures were strongly positively correlated in cases where Rng was known (Pearson's $r=0.94, p<0.01$ ).

To account for a group's nutritional need, we estimated the daily prey energetic requirement (DPER; in kilocalories) at the level of the pod and subunit. Though group size may offer a coarse proxy for a group's nutritional requirements, such requirements vary immensely according to a killer whale's sex, age and reproductive status (Barrett-Lennard et al. 1995; Kriete 1995; Osborne 1999; Williams et al. 2004; Williams and Noren 2009; Noren 2011; Williams et al. 2011). Accordingly, we calculated individuals' DPER values using mass-to-calorie equations described by Noren (2011) and estimated average body masses for age-sex classes noted in Ford et al. (2010a). Because of uncertainty in the energetic costs of growth and lactation, and the effects of those processes on DPER values, we followed a conservative protocol adapted from Noren (2011): all animals' DPERs, except for young juveniles (ages 3-6) and adolescent males (ages 7-12), were calculated using Noren's lower bound equation. To take into account additional energetic costs of rapid growth, DPERs for young juveniles and adolescent males were derived using Noren's upper bound equation.

We accounted for the caloric needs of lactating females by inflating their estimated caloric requirement by $50 \%$ (Kriete 1995; Kastelein et al. 2003). We assumed that any animals less than 2 years of age had their caloric requirements satisfied through consumption of their mothers' milk (Kastelein et al. 
2003). Any adult-aged animals (12+ years) of unknown sex were presumed to have the same requirements as a female of equivalent age, as we assumed that the sexually dimorphic increase in body size seen in males co-occurs with the onset of sexual maturation, which is physically apparent in the rapid growth of their dorsal fin.

Our final three measures concerned the abundance of food resources available to the NRKW population. We used two measures of Chinook salmon abundance, both aggregate indices that included stocks from Washington State to southeast Alaska (USA): (1) terminal run reconstruction estimates for southeast Alaska, northern BC, central BC, west coast Vancouver Island and Georgia Strait (Vélez-Espino et al. 2014), and (2) ocean abundance estimates for the Fraser River, Puget Sound and the upper Columbia River (Pacific Salmon Commission [PSC] 1987-2015). Terminal run reconstructions, as opposed to actual terminal run sizes, attempt to account for the impact of ocean fisheries, thereby providing a more realistic estimate of fish abundance available to oceanic predators such as killer whales (Kope and Parken 2011). The terminal run reconstruction estimates were stock-specific population indices for individual stocks known to be present in NRKW diet (Ford et al. 2010a; Vélez-Espino et al. 2014), whereas ocean abundance estimates provided approximations of cohort sizes from various stocks vulnerable to oceanic fisheries (PSC 1987-2015). Lastly, our third resource abundance measure was an index of chum salmon abundance that included stocks from Washington State to northern BC and consisted of an annual aggregate from three sources: (1) terminal run estimates from southern and central BC (VélezEspino et al. 2013; Fisheries and Oceans Canada 2016), (2) terminal run estimates from northern BC (English et al. 2016) and (3) terminal run estimates for Washington State, including Puget Sound and the outer Washington coast (PSC 19872015). The time series of these Chinook and chum measures are summarized in Supplementary Materials Fig. 3.

\section{Statistical analysis}

We chose to examine group splitting using two independent and distinct techniques: first, we used machine learning to determine the most powerful singular predictors of intrapod cohesion (HWI); and second, we competed candidate generalized linear mixed-effect models (GLMMs) to determine the most important explanatory model for intrapod cohesion in the NRKW population. We conducted all statistical analyses and figure generation in R (version 3.1.2; R Development Core Team 2015).

We used the same dataset for both techniques: our response variable (HWI) and explanatory variables $(n=25)$ were computed annually for each pod $(n=56)$ in the NRKW population in our time series (Supplementary Materials Table 1). Due to temporal limitations of available salmon terminal run reconstruction data, we restricted the time series used in the machine learning and GLMM analyses to 1980-2010. The working dataset contained 564 pod-year records, comprising 13 pods without, and 43 pods with, a living matriarch. The 13 pods without living matriarchs included seven wherein the CUs were assumed to be related through an unknown common maternal ancestor, and six where the common ancestor was either known or presumed (based on probable and certain maternal relationships; see Ford et al. 2000).

We assessed the relative importance and independent effects of our predictor variables using the random forest $(\mathrm{RF})$ machine learning algorithm (Breiman 2001). The regression $\mathrm{RF}$ is an ensemble of independently constructed decision trees, built through the random selection of predictor variables at each node, from which the variable and value that optimizes the split are determined. RF is effectively the mean prediction of the individual trees. Using the $\mathrm{R}$ package randomForest (Liaw and Wiener 2015), we ran a regression RF with 500 trees and eight variables tried at each split to predict the strength of intrapod cohesion (HWI), with sampling stratified by pod ID. We assessed the relative importance of predictors in two ways: accuracy and node purity. These measures indicate the extent to which mean square error (MSE) and residual sum of squares (RSS), respectively, increase when the given variable is randomly permuted - with large changes indicating important variables.

To explore our four hypotheses of the proximate causes of group fission, we compared a set of GLMMs and selected the top-ranked model(s) using Bayesian information criterion (BIC; Schwarz 1978) score comparisons. We used score differences and model weights for inference: models with score differences less than four (when compared to the score of the top-ranked model) were considered among the top model set, and the top-ranked model of this set was considered the single best model if its weight was greater than 0.9 (Burnham and Anderson 2002).

We fit all candidate models $(n=42)$ with a binomial error distribution (logit link function) using the 'glmer' function in the $\mathrm{R}$ package $l m e 4$, which fits models using maximum likelihood (Laplace approximation) (Bates et al. 2015). We accounted for within-group variation in behaviour and repeated measures by including pod ID as a random effect in the models.

We generated our candidate models using combinations of the explanatory variables to describe each of our four hypotheses. Our candidate model set contained models that considered our hypotheses as independent mechanisms, models that considered biologically relevant combinations of our hypotheses and a null model without any fixed effects (Bolker et al. 2008) (Supplementary Materials Table 3). As we predicted that group splitting in the NRKW population ultimately resulted from population growth, we included group size as a fixed effect in all of our candidate models. This allowed us to 
eliminate the effect of group size when comparing models so that we could identify the proximate causes of splitting.

We undertook data exploration of explanatory variables, following protocol described by Zuur et al. (2010). All nonbinary predictor variables were centred (mean-subtracted) and scaled (divided by $2 \mathrm{SD}$ ) to facilitate the interpretation of effect sizes (Gelman 2008; Schielzeth 2010). We removed highly collinear variables (variance inflation factor, VIF > 3) from models; this occurred either through the removal of the more derived collinear variable or by correcting the collinear variable by its correlated counterpart. The latter correction process entailed fitting the relationship between the correlated variables using LOESS smoothing. The residuals of the resulting model were then used as the values for the 'corrected' variable.

\section{Results}

\section{Population dynamics, pod structure and fission}

Over the period of our study, NRKW pods and maternal groups grew in size and their average maternal relatedness decreased, creating conditions favourable for group splitting. The process of permanent group fission was prevalent in the 16 legacy pods, with average intrapod cohesion strongly declining over time and only four legacy pods meeting pod association criteria in 2014 (Supplementary Materials Fig. 4). These four legacy pods consisted of three pods composed of a single maternal group, two of which exhibited little-to-no overall growth over the course of the study and one of which exhibited growth (and has since undergone fission; Towers et al. 2020), and one pod composed of multiple maternal groups that exhibited fluctuating cohesion over the course of the study, splitting apart for multiple years no fewer than two times during the study period.

Splitting in the absence of a matriarch occurred at least once in all but two pods capable of undergoing this type of fission and took place within some pods that had resulted from previous fissions, yielding a total of 35 matriarch-absent splitting events among 11 unique pods between 1973 and 2014. Average cohesion among maternal groups in the population showed a moderate, negative correlation to population size (Pearson's $r=-0.53, p<0.01, n=42$ ). Though observed 38 times during the same period, fission in the presence of a matriarch was less common, occurring in only $50 \%$ of pods capable of this type of splitting $(n=22 / 44)$. Average cohesion within maternal groups exhibited a positive relationship with population size (Pearson's $r=0.39, p=0.032, n=40$ ).

Net changes in the number of pods in the population were not significantly associated with population growth (mean change in number of groups per year $\pm \mathrm{SD}=0.9 \pm 2.9$ (1973-1994), $1.1 \pm 3.9$ (2004-2014)) or the period of no net growth $\left(-0.7 \pm 1.8(1995-2003) ; \mathrm{K}-\mathrm{W} \chi^{2}=3.05, p=0.22\right)$. Rates of fission among the three periods in our time series showed no significant difference from one another $\left(\mathrm{K}-\mathrm{W} \chi^{2}\right.$ $=4.36, p=0.11$; mean splits per year $\pm \mathrm{SD}=1.74 \pm 1.42$ ), while rates of fusion were significantly higher during the period of no net growth $\left(\mathrm{K}-\mathrm{W} \chi^{2}=7.86, p=0.02\right.$; mean reunions per year $\pm \mathrm{SD}=2.44 \pm 1.94(1995-2003))$ than in the periods of rapid growth $(0.77 \pm 1.15(1973-1994), 1.27 \pm 1.19$ (2004-2014)).

The number of pods present within the population from 1973-2014 was strongly positively associated with population size (Pearson's $r=0.83, p<0.01, n=42$ ); on average, for every 17 animals added to the population as a whole, a new pod formed. The size and structure of pods were also closely coupled with population size, with the mean number of CUs per pod decreasing (Pearson's $r=-0.66, p<0.01, n=42$ ) and the number of individuals per $\mathrm{CU}$ increasing as population size increased (Pearson's $r=0.96, p<0.01, n=42$ ). Pod sizes observed during our study ranged from 3 to 25 individuals and averaged 8 individuals. The minimum annual average pod size was observed in 1977 (6.3 individuals) and the maximum annual average pod size was seen in 2007 (9.2 individuals). Overall, the mean number of individuals per pod showed a weak positive correlation with population size (Pearson's $r=$ $0.51, p<0.01, n=42$ ).

\section{Patterns of fission}

Group splitting in NRKWs followed consistent patterns. In all fission events, resulting groups became discrete pods, rather than merging with others. Also, fission was kin-biased; resulting pods were always matrilineal, with individuals remaining with their direct maternal relatives.

In matriarch-present fission events, the split always occurred between the matriarch and her eldest daughter still remaining in the group. In all cases, the eldest daughter was that with the most maternal descendants. Additionally, matriarch-present splitting never occurred in pods composed of more than one CU.

\section{Longevity of fission}

According to our Kaplan-Meier analysis, the overall probability that fissioned pods would ultimately reunite was low, at $34 \%$ (Fig. 3). However, this probability was markedly different depending on the type of splitting that occurred; pods exhibiting matriarch-absent fission had a $25 \%$ probability of reunion, whereas those that underwent matriarch-present fission had a $70 \%$ probability of reunion.

Typically, pods that reunited did so within the first 3 years after splitting (mean $=2.5$ years; median $=2$ years , with a 

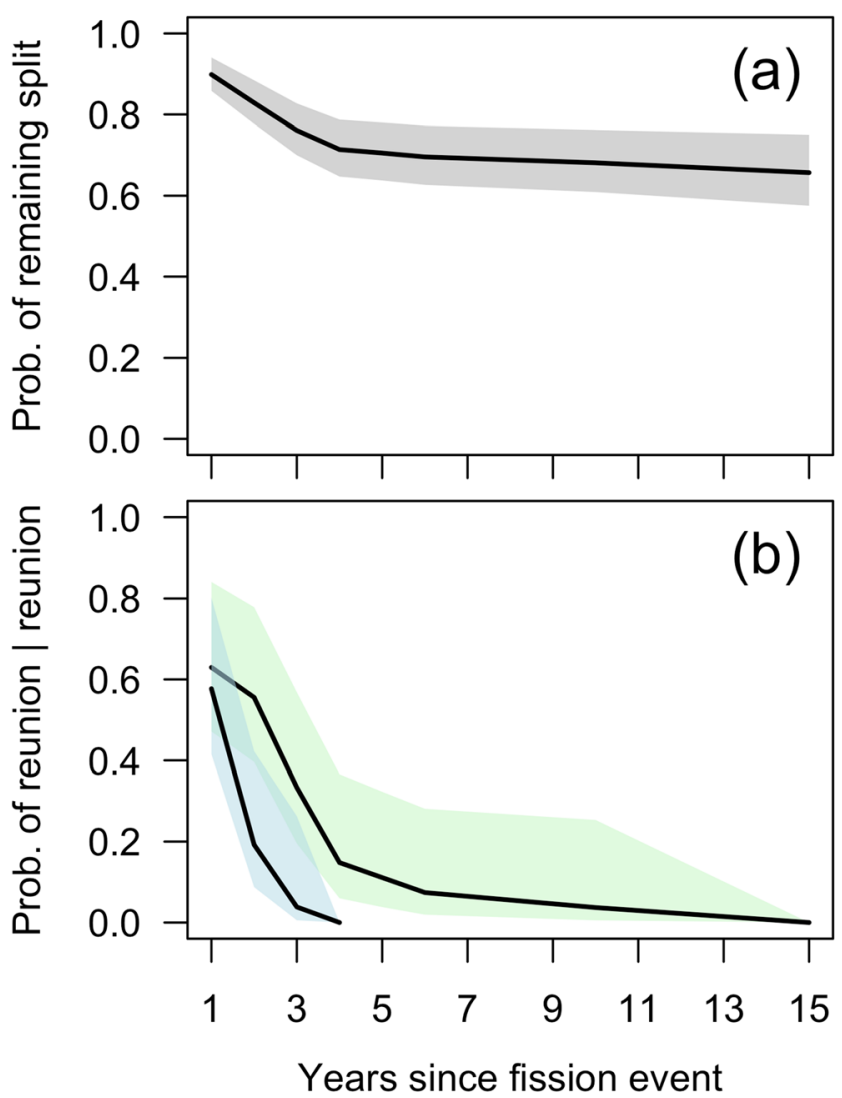

Fig. 3 Longevity of group fission according to a the probability that a pod will remain split and $\mathbf{b}$ the time-sensitive probability of reuniting (given a pod will reunite) according to the type of splitting the pod exhibited (fission in the absence [green] and presence [blue] of a matriarch), as a function of the time elapsed since a fission event

$60 \%$ probability that the reunion occurred the year following the split. In only $2 \%$ of cases ( $n=1 / 53$ reunions), fusion occurred more than 10 years after splitting. The longest duration between splitting and reuniting was 15 years $(n=1)$. In this case, the strong re-association of pod members was temporary, lasting only one sampling period (June-October) before fission occurred again, along the same maternal lines as the original split. All reunions with a matriarch $(n=26)$ occurred within 4 years of splitting; the probability of reunion occurring more than 2 years after fission was less than $4 \%$. In contrast, the probability of a reunion in the absence of a matriarch $(n=27)$ occurring more than 2 years after a fission event remained high (cumulative probability of $70 \%$; Fig. 3).

This difference was reflected in the observed durations of the two splitting processes. Permanent splitting in the absence of a matriarch tended to be drawn out; often two decades passed between an apparent weakening of intrapod cohesion and consistent social separation (mean $\pm \mathrm{SD}=20.2 \pm 11.9$ years). The process of permanent splitting in the presence of a matriarch tended to occur on a much shorter time scale (mean $\pm \mathrm{SD}=6.9 \pm 5.6$ years $)$.

\section{Determinants of group fission}

\section{Machine learning}

When scoring variable importance by accuracy (percent increase in mean square error, \%incMSE), the RF algorithm ranked the total estimated daily caloric requirement of the pod as the top predictor (\%incMSE $=29.0$ ) of intrapod cohesion. The second-ranked predictor, the submatriarch's relative relatedness (Rxm), was significantly less important (\%incMSE $=18.1$ ) and was followed closely by the remaining 23 predictors in continuously decreasing importance. The lowest-ranked predictor was Chinook salmon terminal run abundance (\%incMSE $=0.3$ ). Variable importance ranked by the increase in node purity (incNP) was very similar to that ranked by accuracy, with DPERg assessed as the top-ranked predictor (incNP $=13.3$ ) and all other 24 predictors following distantly, from the second-ranked predictor, group size (incNP $=6.5$ ), to the lowest-ranked predictor, matriarch presence (incNP $=0.5$ ).

As a singular predictor, the estimated daily caloric requirement of a pod predicts continuously decreasing intrapod cohesion with the increasing nutritional needs of the group, with out-of-bag predictions of HWI explaining 57.9\% of the target variance of the training set (MSE $=0.05$ ). The predicted probability of intrapod cohesion drops below $50 \%$ as a group's caloric needs reach approximately two million kilocalories per day.

\section{Generalized modelling}

According to BIC scoring, a single top-ranked GLMM predicted intrapod cohesion with $100 \%$ of the model weight. Of the eleven variables in the top model, seven were statistically significant and associated with each of our hypotheses: group size, relative submatriarch relatedness, proportion of physically mature males, age of submatriarch, proportion of lactating subunit females, chum salmon terminal run abundance and Chinook salmon ocean abundance (Supplementary Materials Fig. 5). Based on post hoc assessment of residuals, this model explained intrapod cohesion of pods with and without living matriarchs with similar success, suggesting that there is no apparent difference in the drivers of the two fission processes.

According to our top-ranked GLMM, group size had the greatest effect on intrapod cohesion, predicting lower cohesion with increasing group size (Supplementary Materials Fig. 5; Fig. 4a). All but two of the food competition variables were statistically significant predictors of intrapod cohesion: higher proportions of physically mature males in the pod predicted weaker intrapod cohesion (Fig. 4b), while increases in Chinook ocean abundance and chum terminal run abundance predicted a slight positive association with intrapod cohesion (Fig. 4d). 
(a)

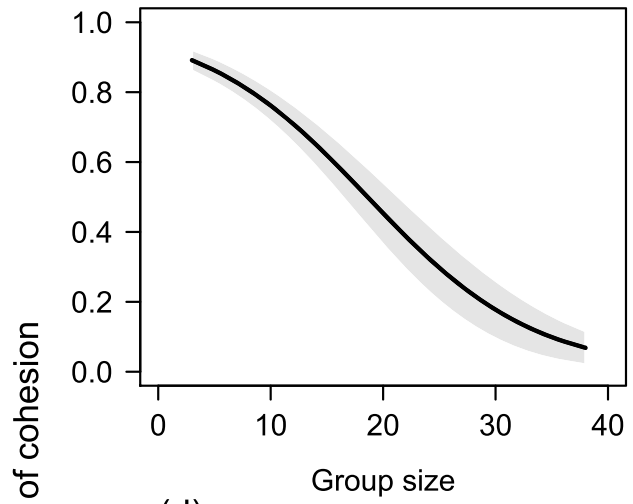

(d)

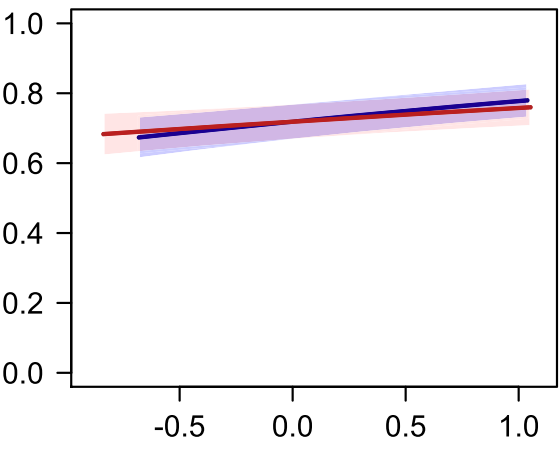

Salmon abundance (b)

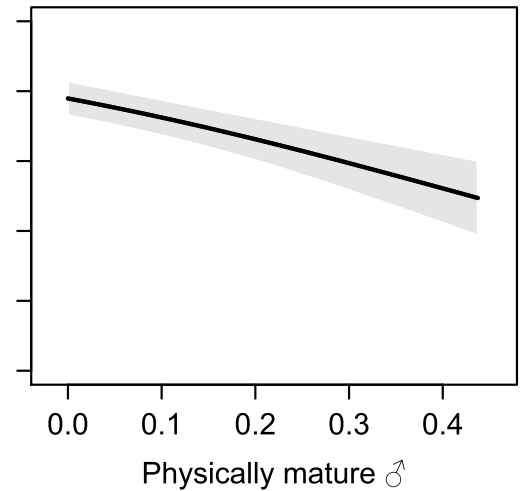

(e)

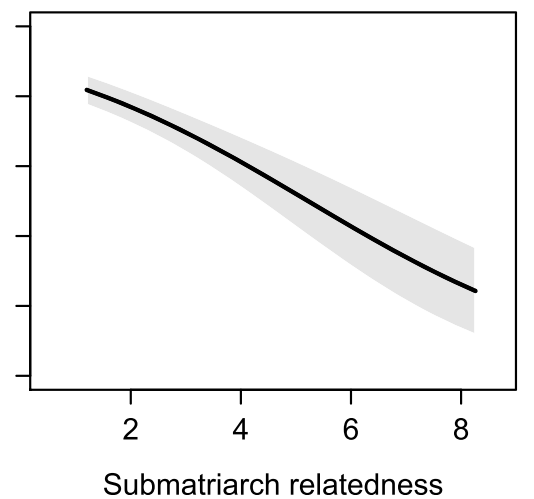

(c)

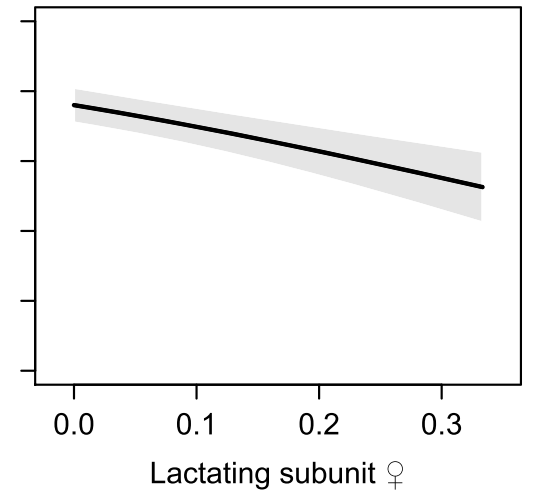

(f)

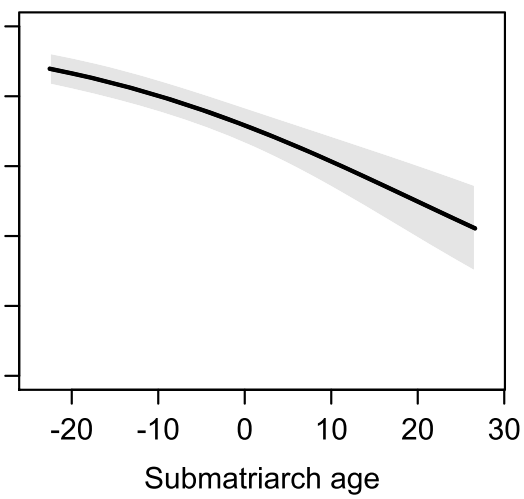

Fig. 4 Probability of intrapod cohesion as predicted by significant predictors of our top GLMM, when setting all other predictor variables to their mean values. a Group size (number of individuals in pod). b Number of physically mature males (as a proportion of group size). c Number of lactating subunit females (as a proportion of group size). d Centralized Chinook salmon ocean abundance (blue) and centralized

Reproductive conflict, represented by the proportion of lactating females in the subunit, was a significant predictor of intrapod cohesion, with higher proportions of lactating subunit females predicting weaker cohesion (Fig. 4c). Most splits with a matriarch $(85 \% ; n=29 / 34)$ during our restricted time series (1980-2010) involved daughters fissioning with a postreproductive matriarch. Of the five splits involving a matriarch of reproductive age during this period, four $(12 \% ; n=$ 4/34) coincided with the matriarch and her daughter having overlapping lactation periods due to synchronous calving. Lactating females were present in both the subunit and the rest of the pod in $25 \%$ of all splitting events during this time period $(n=16 / 63)$, and present only in the subunit in $41 \%(n=26 / 63)$ of these events.

The two remaining significant predictors identified by our top model were associated with our kinship and leadership hypotheses. Relative submatriarch relatedness had a strong effect on intrapod cohesion, predicting weaker cohesion as the submatriarch's relatedness to her direct descendants increased relative to her relatedness to the rest of her pod (Fig. $4 \mathrm{e})$. The age of the submatriarch was also a significant predictor in our top model. When the submatriarch was older than chum salmon terminal run abundance (red). e Relative relatedness of the submatriarch (i.e. the submatriarch's average relatedness to her subunit is $x$ times greater than her average relatedness to the rest of her pod). $\mathbf{f}$ Age of the submatriarch (corrected for group size; i.e. $n$ years older $(+)$ or younger (-) than the average age of submatriarchs of the same size pod). $95 \%$ confidence bands denoted by shading

the average submatriarch of a comparably sized pod, weaker intrapod cohesion was observed; whereas if she was younger than the average submatriarch of a comparably sized pod, stronger intrapod cohesion was observed (Fig. 4f).

\section{Discussion}

Nearly 50 years after the study of killer whales in the eastern North Pacific began, studies of resident-type killer whales have revealed further complexities of killer whale society. Throughout resident killer whale populations, there is often considerable dynamism in associations observed among pod members over time (Ford and Ellis 2002; Parsons et al. 2009). We now recognize the pod as a social grouping that may only maintain cohesion for a decade or less, presumably due to population growth, demographics or ecological factors. The temporary condition of the pod raises questions about the nomenclature used to describe resident social structure: what do we call pods when they are no longer pods? How do we describe the structure of dynamic social groupings so that they are comparable across years or decades? 
Here, we have chosen to retain the term 'pod' for all assemblages of maternal groups that meet the Bigg et al. (1990) criteria at a given time. To distinguish newly formed pods from those originally delineated by Bigg et al. (1990), we use the term 'legacy pod' for pods that have historically existed.

Pods and maternal groups can exhibit varying degrees of maternal relatedness, where a group's common maternal ancestor may be more or less recent, alive or dead, and where female survival may differ, resulting in more or less fragmented groups. As a result of this complexity, we suggest new nomenclature for group structures based on matrilineal units: 'basal units', 'nested units' and 'complete units'. These terms allow social groupings at any level of resident social structure to be described consistently over time and are particularly helpful in light of maternal group splitting, as they provide functional subsets of the maternal group. Complete and nested units must be led by an extant female who is a direct maternal ancestor to all in her unit, which therefore excludes individuals with no living mother and no local offspring (Supplementary Materials Fig. 1). This nomenclature scheme is therefore limited in describing highly fragmented groups and in examining potential fission involving groups of motherless and childless individuals (e.g. orphaned kin separating from grandmother or aunt). This type of group splitting, while not exhibited during the time period of our analysis, has since been observed in the NRKW population (Towers et al. 2020).

Population growth may influence group structure and lead to group splitting, specifically when growth results in a small number of large matrilines per social group and negative or slow growth results in social groups composed of several smaller matrilines (Melnick and Kidd 1983; Lefebvre et al. 2003). Both scenarios may result in group splitting: in the former, groups grow to an unsustainable size, and in the latter, groups are assemblages of small, weakly bonded units. In both cases, splitting is likely due to the decline in inclusive benefits of cooperation resulting from weakened kinship among group members. The NRKW population has steadily increased in size and as of 2014 was 2.5 times larger than it was in 1973, with growth rates nearing and sometimes exceeding the $4 \%$ maximum theoretical rate of increase typical of cetaceans (Wade 1998). Given such high population growth and the strong natal social philopatry exhibited by both sexes, new pods were expected to arise in the NRKW population through the process of matrilineal fission (Bigg et al. 1990). Our analysis shows that, though fission does not appear to be directly driven by population growth, the number of pods present within the population is strongly linked to the population's size; roughly, for every 17 animals added to the population as a whole, a new pod formed. Similarly, from a group perspective, our model findings predict that as an NRKW pod grows its probability of remaining a cohesive social unit decreases. An NRKW pod's probability of cohesion drops below 50\% when its size reaches 20 individuals (according to our top GLMM) or when its daily caloric need reaches two million kilocalories (equivalent to approximately 122 Chinook salmon averaging $9.8 \mathrm{~kg}$ each, Stredulinsky 2016; according to our RF results). These caloric needs are typically found in NRKW groups composed of 10-15 individuals.

Group splitting in the NRKW population occurred in a predictable manner. This was especially notable in the relative frequency of matriarch-absent and matriarch-present fission, with splitting occurring more frequently in the absence of a matriarch, when accounting for the number of pods capable of each type of fission. The differential frequency between the two processes was expected, as it is commonly observed in other species that exhibit matrilineal fission, where groups preferentially split along maternal lines rather than across them, thereby maximizing the maternal relatedness of the resulting groups (Lefebvre et al. 2003; Widdig et al. 2006; Lawson Handley and Perrin 2007).

Splitting in the presence of a matriarch always involved the oldest daughter still remaining in the group splitting from the matriarch with her maternal descendants. Similar patterns of fission in primate populations have been attributed to reverse dominance ranks among sisters (e.g. Chepko-Sade and Sade 1979; Chapais 2004). In rhesus monkeys (Macaca mulatta), mature sisters rank in the inverse order of their ages, with the oldest receiving the lowest rank among her sisters (Datta 1988; Holekamp and Smale 1991). In this case, the oldest daughter, being the social subordinate, is 'peripheralized' by her group and disperses (Christian 1970). In NRKW, mothers share prey with their daughters less frequently as a daughter ages, but this correlation is more strongly linked to the existence of the daughter's offspring than her birth rank (Wright et al. 2016). In our study, submatriarchs in matriarch-present fissions were always the leaders of the largest nested unit within their respective pods, and thus we cannot test the effect of relative nested unit size on fission separately from the effect of submatriarch birth rank. Should subunits in these splits continue to be the largest nested units in their pods, regardless of differences in submatriarch birth rank, unit size is likely delineating the subunit. Conversely, should the subunits in these splits continue to be led by the oldest daughter, despite not leading the largest nested unit in her pod, other mechanisms for subunit delineation, such as dominance structures, are likely at play. This would require further investigation, as no dominance interactions have yet been documented among female resident killer whales.

Leadership experience could also explain why the oldest submatriarch was involved in fissioning. The presence of a matriarch promotes intragroup cohesion in many matrifocal mammalian species (e.g. Chepko-Sade and Sade 1979; Wittemyer et al. 2005; Archie et al. 2006; Berry and Bercovitch 2014). Perhaps most importantly, as the oldest member of the group, a matriarch is her group's richest source 
of ecological and social knowledge and, through social transmission, can enhance her group's collective knowledge (McComb et al. 2001; McAuliffe and Whitehead 2005). Her leadership undoubtedly affects her group's wellbeing (Foley et al. 2008; McComb et al. 2011; Berry and Bercovitch 2014; Brent et al. 2015) and may influence group members' dispersal decisions. The fitness costs of reduced contact with the matriarch could delay a subunit's social dispersal until the submatriarch has acquired sufficient knowledge from the matriarch (e.g. Lutermann et al. 2006). This may be the case in NRKWs, where our GLMM results suggest that pods with older submatriarchs were more likely to split than were comparably sized pods with younger submatriarchs.

Behaviours that strengthen and maintain social bonds among individuals but are costly to the individual can delineate substructures within groups. Given that animals can be limited as to the number of individuals with which they can conduct interactions, they may be unable to maintain strong bonds with all individuals within their group, beyond a certain group size (e.g. Kudo and Dunbar 2001; Shultz and Dunbar 2007; Pollard and Blumstein 2008; Lehmann and Dunbar 2009; Bergmüller et al. 2010; Dávid-Barrett and Dunbar 2013). Preferential relationships in many social species are dictated by maternal relatedness (Gouzoules 1984; Walters 1987; Wittemyer et al. 2005; Berman et al. 2008), which can also be an indicator of familiarity among individuals (Chapais 2001; Majolo et al. 2008) and is a good predictor of group fission in various species (Chepko-Sade and Olivier 1979; Archie et al. 2006; Widdig et al. 2006; Van Horn et al. 2007; Sueur et al. 2011).

Our results suggest that pod substructuring, delineated by maternal kinship, is an important correlate of group splitting in NRKWs. Although group structure described by the number and mean size of CUs within a pod did not show a strong effect on NRKW intrapod cohesion, a submatriarch's relative relatedness was a significant predictor of cohesion. In populations such as this, with philopatric males and non-local mating, a female's local relatedness increases with age as she produces offspring (Johnstone and Cant 2010; Croft et al. 2017). As a submatriarch's relative relatedness increases, the inclusive fitness benefits resulting from her cooperation with non-lineal relatives may be reduced, particularly compared to those gained from aiding her direct descendants (Frank 2013). This weakened kinship, in turn, may lead to greater substructuring (Lefebvre et al. 2003), where weakening interactions between the subunit and other pod members may result in reduced intrapod cohesion and an increased probability of group fission.

In resident killer whales, maternal relatedness drives differential prey sharing (Wright et al. 2016), a behaviour that, in other species, may allow parental control of dispersal (Ekman and Rosander 1992). Notably, maternal provisioning of offspring in NRKWs declines as offspring mature, particularly for daughters as they reach reproductive maturity and produce their first offspring (Wright et al. 2016). If kin-directed prey sharing reinforces social bonds among resident killer whale individuals, the behaviour may delineate group substructures, where social bonds among individuals of different basal units may be weaker.

Having established group size as the ultimate cause of pod splitting in NRKWs, we then considered why large group sizes in this population might be so costly. Intragroup competition for food was the most strongly supported hypothesis in both our GLMM and RF findings. Group splitting among social animals can optimize feeding opportunities and alleviate competition for food among group members (e.g. Dittus 1988; Whitehead and Weilgart 2000; Ren et al. 2012; Schaffner et al. 2012). A group's nutritional requirement is determined by the number of animals in the group and the proportion of animals that require more food due to metabolic processes such as growth and lactation. We predicted that increased group metabolic requirements would adversely affect intrapod cohesion, because (a) time spent socializing would be sacrificed in favour of foraging to satisfy nutritional needs, thus weakening social bonds within the group, and/or; (b) competition for food among pod members would increase, thus promoting group splitting to improve per capita prey availability.

Our GLMM results indicate that NRKW pods with higher proportions of physically mature males and lactating subunit females had lower intragroup cohesion and a higher probability of fission. A similar negative correlation between males and their group's cohesion has been observed in resident-type killer whales in the western North Pacific (Ivkovich et al. 2010; Filatova et al. 2017). Physically mature males and lactating females have a disproportionate impact on their group's nutritional needs (Noren 2011). Mature males, in particular, have high caloric requirements but contribute little to intragroup prey sharing (Wright et al. 2016). A fully grown male may require 13-16 Chinook salmon (averaging $9.8 \mathrm{~kg}$ each) per day, 2-3 times the calories required by a young animal (Stredulinsky 2016). Likewise, a lactating female may be required to catch roughly five more fish each day than her non-lactating counterparts (Stredulinsky 2016), increasing her food intake by 1.5-2 times, especially in the first few months of producing milk (Kriete 1995; Kastelein et al. 2003; Noren 2011).

According to our GLMM results, synchronous lactation within a pod increased the probability that the pod would undergo fission, which suggests that group splitting may be a way to avoid reproductive conflict. In long-lived socially philopatric species such as resident killer whales, the probability of an older female breeding at the same time as younger, closely related females in the same group is high. Younger females have the selective advantage in this inter-generational reproductive conflict, with older females having significantly 
less reproductive success than their co-breeding daughters, and thus this reproductive conflict is suggested to have contributed to the evolution of menopause in resident killer whales (Croft et al. 2017). However, the inter-generational (mother-daughter) conflict central to reproductive conflict theory may have only played a small role in the group fission we observed in this population; the great majority of matriarchpresent splits involved a post-reproductive matriarch and few splits coincided with a reproductive matriarch and her daughter in direct reproductive conflict. Additionally, there is limited evidence that splitting alleviated broader reproductive conflict between females in the subunit and those in the remainder of the pod; lactating females were present in both groups in only $25 \%$ of splitting events. Further, as the proportion of lactating subunit females out-competed lactating females from the whole pod at predicting intrapod cohesion, splitting was likely influenced by insufficient prey availability to females (e.g. Isbell and van Vuren 1996) rather than by avoidance of reproductive conflict between the subunit and other pod members.

Although we expected that higher median group age would predict lower intrapod cohesion because of the increased food requirements of mature individuals, median group age was not a significant predictor of intrapod cohesion in our top-ranked GLMM. From an energetic standpoint, a pod's caloric needs increase as it contains more mature individuals, which in turn might promote fission to alleviate food competition among pod members. Alternatively, mature individuals (especially females) typically contribute the most to caretaking, foraging and prey sharing, behaviours that likely promote social cohesion (Waite 1988; Wright et al. 2016). These competing consequences of age may explain the lack of significance of our age predictor variable. Further, this absence of significant statistical association may be the reason for the disparity between our RF and GLMM results, wherein DPER was found to be an important predictor in the former but not the latter. DPER was the best singular predictor of intrapod cohesion selected by our RF analysis. Our best GLMM model, however, did not include DPER but rather incorporated all individual components from which DPER is derived: number, age and reproductive status of individuals in the group. With the capacity to assess the additive effects of several predictors, our GLMM results showed all components of DPER except age to be strongly relevant to group splitting.

If groups split at a relatively predictable group size, intrinsic - rather than environmental-factors are thought to be primarily responsible for fission (Thierry et al. 2004; Sueur and Maire 2014). However, extrinsic pressures can have a direct impact on the population dynamics and characteristics of a group (Sueur et al. 2011) and may affect the favourability of a group's demographic conditions (e.g. Ekman and Rosander 1992), and therefore may still be important auxiliary factors in group fission. While our findings indicated demographic effects have a greater influence on NRKW intrapod cohesion than environmental factors, two of our salmon abundance predictors remained important explanatory variables in our top-ranked GLMM. Higher abundances of both Chinook and chum salmon (particularly ocean abundance and terminal run abundance, respectively) predicted higher intrapod cohesion. Chinook salmon, which dominates resident killer whale diet from June to September (Ford and Ellis 2006; Ford et al. 2010a; Hanson et al. 2010), is a significant correlate of resident killer whale survival and fecundity (Ward et al. 2009; Ford et al. 2010b; Vélez-Espino et al. 2014) and has also previously been identified as a correlate of social behaviours in resident killer whales, with years of low Chinook abundance associated with smaller group sizes and weaker social network connectivity (Lusseau et al. 2004; Foster et al. 2012). Chum salmon (Oncorhynchus keta) is an important component of NRKW diet, surpassing Chinook salmon frequency in NRKW diet in early fall (SeptemberOctober) (Ford and Ellis 2006; Ford et al. 2010a). Chum salmon abundance is a useful predictor of resident killer whale vital rates (Vélez-Espino et al. 2013), but has not been examined as a predictor of resident killer whale social behaviour prior to this study. Our findings support the growing body of evidence suggesting changes in the quantity and quality of these important prey species affect not only the survival and fecundity of resident killer whale populations but have significant influence on their social dynamics as well.

\section{Conclusion}

We demonstrate that large group size drives group splitting in NRKWs and that population growth does not appear to influence the rate at which group fission occurs. Intrinsic group characteristics associated with food competition within large pods provide strong correlates of group splitting in this population, particularly those dictating groups' nutritional requirements (e.g. lactation) and the distribution of food competition within groups (due to substructuring delineated by maternal kinship, likely mediated by kin-directed behaviours like prey sharing). Though food competition within groups is a strong predictor of group splitting, prey abundance has only a marginal effect on intrapod cohesion. Splitting also appears to be inhibited in the absence of adequate leadership; pods require a submatriarch of sufficient experience before group splitting can occur.

Matrilineal fission may have profound effects on an individual's fitness, a population's genetic structure, and processes involving the vertical transmission of knowledge (such as acoustic dialect evolution). We encourage future studies to examine the consequences of matrilineal fission in resident killer whales, for which this work provides a foundation. Our findings further underscore the importance of 
incorporating social dynamics into the management of threatened populations of killer whales.

Supplementary Information The online version contains supplementary material available at https://doi.org/10.1007/s00265-021-02992-8.

Acknowledgments The killer whale data used in this study are the result of long-term collaborative fieldwork. We are exceptionally grateful to the many colleagues and volunteers who participated in both fieldwork and data entry over the past 48 years, especially the late Dr. Michael Bigg, and past and present members of Fisheries and Oceans Canada's Cetacean Research Program. This long-term study has been supported by the Species at Risk Program of Fisheries and Oceans Canada since 2000. We wish to acknowledge Karl English, David Peacock, Pieter Van Will, Antonio Vélez-Espino and Ivan Winther for their provision of and/or guidance regarding Chinook and chum salmon data. We appreciate the advice provided by Andrew Bateman, Antonio Vélez-Espino and Brianna Wright regarding study design. We thank Uko Gorter for the original artwork used in Fig. 2 and Supplementary Materials Fig. 1. Thank you to Brianna Wright, James Pilkington, Jane Watson, Sara Tavares, Christine Konrad and the anonymous reviewers for providing comments on earlier versions of this manuscript. This work was supported by the Natural Sciences and Engineering Research Council of Canada, Fisheries and Oceans Canada, the Vancouver Aquarium and the University of Victoria's Applied Conservation Science Lab.

Funding This study was funded by a National Sciences and Engineering Research Council of Canada (NSERC) IPS1 award granted to EHS, in partnership with the Vancouver Aquarium Marine Science Centre and Fisheries and Oceans Canada.

Data availability The datasets derived and analysed during the current study are available in Electronic Supplementary Materials and in the Open Government repository: https:/open.canada.ca/data/en/dataset/ 8c773994-1031-411b-a1ad-933928daa4ac.

\section{Declarations}

Ethics approval and consent to participate All applicable international, national and institutional guidelines for the care and use of animals were followed. Data used in this study were collected under Fisheries and Oceans Canada Marine Mammal Research License no. MML-001. All field procedures were approved by the Pacific Region Animal Care Committee of Fisheries and Oceans Canada (Pacific Biological Station), and complied with the standards of animal care set by the Canadian Council on Animal Care.

\section{Consent for publication Not applicable}

Conflict of interest The authors declare that they have no conflict of interest.

Open Access This article is licensed under a Creative Commons Attribution 4.0 International License, which permits use, sharing, adaptation, distribution and reproduction in any medium or format, as long as you give appropriate credit to the original author(s) and the source, provide a link to the Creative Commons licence, and indicate if changes were made. The images or other third party material in this article are included in the article's Creative Commons licence, unless indicated otherwise in a credit line to the material. If material is not included in the article's Creative Commons licence and your intended use is not permitted by statutory regulation or exceeds the permitted use, you will need to obtain permission directly from the copyright holder. To view a copy of this licence, visit http://creativecommons.org/licenses/by/4.0/.

\section{References}

Archie EA, Moss CJ, Alberts SC (2006) The ties that bind: genetic relatedness predicts the fission and fusion of social groups in wild African elephants. Proc R Soc Lond B 273:513-522

Armitage KB (1987) Social dynamics of mammals: reproductive success, kinship and individual fitness. Trends Ecol Evol 2:279-284

Baird RW, Whitehead H (2000) Social organization of mammal-eating killer whales: group stability and dispersal patterns. Can J Zool 78: 2096-2105

Barrett-Lennard L (2000) Population structure and mating patterns of killer whales (Orcinus orca) as revealed by DNA analysis. Dissertation, University of British Columbia

Barrett-Lennard LG, Heise K, Saulitis E, Ellis G, Matkin C (1995) The impact of killer whale predation on Steller sea lion populations in British Columbia and Alaska. Report to the North Pacific Universities Marine Mammal Research Consortium, Vancouver, Canada, http://www.marinemammal.org/wp-content/pdfs/Barrett etal1995-killer.pdf

Bates D, Maechler M, Bolker B, Walker S (2015) Package 'lme4': linear mixed-effects models using 'Eigen' and S4. R package, version 1.1.7, https://cran.r-project.org/web/packages/lme4/lme4.pdf

Bergmüller R, Schürch R, Hamilton IM (2010) Evolutionary causes and consequences of consistent individual variation in cooperative behaviour. Phil Trans R Soc B 365:2751-2764

Berman CM, Ogawa H, Ionica C, Yin H, Li J (2008) Variation in kin bias over time in a group of Tibetan macaques at Huangshan, China: contest competition, time constraints or risk response? Behaviour 145:863-896

Berry PSM, Bercovitch FB (2014) Leadership of herd progressions in the Thronicroft's giraffe of Zambia. Afr J Ecol 53:175-182

Bigg MA (1982) An assessment of killer whale (Orcinus orca) stocks off Vancouver Island, British Columbia. Rep Int Whaling Comm 32: 655-666

Bigg MA, MacAskie IB, Ellis GM (1976) Abundance and movements of killer whales off eastern and southern Vancouver Island with comments on management. Preliminary report, Arctic Biological Station, Ste. Anne de Bellevue, Quebec, Canada

Bigg MA, Ellis GM, Ford JKB, Balcomb KC (1987) Killer whales: a study of their identification, genealogy and natural history in British Columbia and Washington State. Phantom Press, Nanaimo

Bigg MA, Olesiuk PF, Ellis GM, Ford JKB, Balcomb KC III (1990) Social organization and genealogy of resident killer whales (Orcinus orca) in the coastal waters of British Columbia and Washington State. Rep Int Whaling Comm 12:383-405

Bolker B, Brooks ME, Clark CJ, Geange SW, Poulsen JR, Stevens MHH, White JSS (2008) Generalized linear mixed models: a practical guide for ecology and evolution. Trends Ecol Evol 24:127-135

Breiman L (2001) Random forests. Mach Learn 45:5-32

Brent LJN, Franks DW, Foster EA, Balcomb KC, Cant MA, Croft DP (2015) Ecological knowledge, leadership, and the evolution of menopause in killer whales. Curr Biol 25:746-750

Burnham KP, Anderson DR (2002) Model selection and multimodel inference, 2nd edn. Springer-Verlag, New York

Cairns SJ, Schwager SJ (1987) A comparison of association indices. Anim Behav 35:1454-1469

Center for Whale Research (2016) Southern resident killer whales: 2016 matriline ID guide. Report by Center for Whale Research, Friday Harbor 
Chapais B (2001) Primate nepotism: what is the explanatory value of kin selection? Int J Primatol 22:203-229

Chapais B (2004) How kinship generates dominance structures: a comparative perspective. In: Thierry B, Singh W, Kaumanns W (eds) Macaque societies: a model for the study of social organization. Cambridge University Press, Cambridge, pp 186-203

Chepko-Sade BD, Olivier TJ (1979) Coefficient of genetic relationship and probability of intragenealogical fission in Macaca mulatta. Behav Ecol Sociobiol 5:263-278

Chepko-Sade BD, Sade DS (1979) Patterns of group splitting within matrilineal kinship groups: a study of social group structure in Macaca mulatta. Behav Ecol Sociobiol 5:67-86

Christian JJ (1970) Social subordination, population density, and mammalian evolution. Science 168:84-90

Clutton-Brock TH, Lukas D (2012) The evolution of social philopatry and dispersal in female mammals. Mol Ecol 21:472-492

Croft DP, Johnstone RA, Ellis S, Nattrass S, Franks DW, Brent LJN, Mazzi S, Balcomb KC, Ford JKB, Cant MA (2017) Reproductive conflict and the evolution of menopause in killer whales. Curr Biol $27: 1-7$

Datta SB (1988) The acquisition of dominance among free-ranging rhesus monkey siblings. Anim Behav 36:754-772

Dávid-Barrett T, Dunbar RIM (2013) Processing power limits social group size: computational evidence for the cognitive costs of sociality. Proc R Soc B 280:20131151

Deecke VB, Barrett-Lennard LG, Spong P, Ford JKB (2010) The structure of stereotyped calls reflects kinship and social affiliation in resident killer whales (Orcinus orca). Naturwissenschaften 97: $513-518$

DFO - Fisheries and Oceans Canada (2019) Population status update for the Northern Resident Killer Whale (Orcinus orca) in 2018. DFO Can Sci Advis Sec Sci Resp \2019/025, https://waves-vagues.dfompo.gc.ca/Library/40818950.pdf

DFO - Fisheries and Oceans Canada Cetacean Research Program (2015) [Northern Resident Killer Whale population census data from 19732015]. Courtesy of John Ford (DFO - Nanaimo)

Dittus WPJ (1988) Group fission among wild toque macaques as a consequence of female resource competition and environmental stress. Anim Behav 36:1626-1645

Ekman J, Rosander B (1992) Survival enhancement through food sharing: a means for parental control of natal dispersal. Theor Popul Biol 42:117-129

English KK, Peacock D, Challenger W, Mochizuki T (2016) North and Central coast salmon escapement, catch, run size and exploitation rate estimates for each salmon conservation unit for 1954-2014. LGL Limited report prepared for, Pacific Salmon Foundation and Fisheries and Oceans Canada http://skeenasalmonprogram.ca/ libraryfiles/lib_435.pdf

Esteban R, Verborgh P, Gauffier P, Giménez J, Foote AD, de Stephanis R (2015) Maternal kinship and fisheries interaction influence killer whale social structure. Behav Ecol Sociobiol 70:111-122

Filatova OA, Ivkovich TV, Guzeev MA, Burdin AM, Hoyt E (2017) Social complexity and cultural transmission of dialects in killer whales. Behaviour 154:171-194

Fisheries and Oceans Canada (2016) [Chum salmon terminal run time series dataset, fishery areas 11-29]. Courtesy of Pieter Van Will (DFO - South Coast)

Foley C, Pettorelli N, Foley L (2008) Severe drought and calf survival in elephants. Biol Lett 4:541-544

Ford JKB (1989) Acoustic behaviour of resident killer whales (Orcinus orca) off Vancouver Island, British Columbia. Can J Zool 67:727745

Ford JKB (1991) Vocal traditions among resident killer whales (Orcinus orca) in coastal waters of British Columbia. Can J Zool 69:1454 1483
Ford JKB, Ellis GM (2002) Reassessing the social organization of resident killer whales in British Columbia. In: Proceedings of the Fourth International Orca Symposium and Workshops. CEBC-CNRS, France, pp 72-74

Ford JKB, Ellis GM (2006) Selective foraging by fish-eating killer whales Orcinus orca in British Columbia. Mar Ecol-Prog Ser 316: 185-199

Ford JKB, Ellis GM, Barrett-Lennard LG, Morton AB, Palm RS, Balcomb KC (1998) Dietary specialization in two sympatric populations of killer whales (Orcinus orca) in coastal British Columbia and adjacent waters. Can J Zool 76:1456-1471

Ford JKB, Ellis GM, Balcomb KC III (2000) Killer whales: the natural history and genealogy of Orcinus orca in British Columbia and Washington State. University of British Columbia Press, Vancouver

Ford JKB, Ellis GM, Olesiuk PF, Balcomb KC (2010a) Linking killer whale survival and prey abundance: food limitation in the oceans' apex predator? Biol Lett 6:139-142

Ford JKB, Wright BM, Ellis GM, Candy JR (2010b) Chinook salmon predation by resident killer whales: seasonal and regional selectivity, stock identity of prey, and consumption rates. DFO Can Sci Advis Sec Res Doc 2009/101, https://waves-vagues.dfo-mpo.gc.ca/ Library/339995.pdf

Foster EA, Franks DW, Morrell LJ, Balcomb KC, Parsons KM, van Ginneken A, Croft DP (2012) Social network correlates of food availability in an endangered population of killer whales, Orcinus orca. Anim Behav 83:731-736

Frank SA (2013) Natural selection. VII. History and interpretation of kin selection theory. J Evol Biol 26:1151-1184

Furuya Y (1968) On the fission of troops of Japanese monkeys. I. Five fissions and social changes between 1955 and 1966 in the Gayusan troop. Primates 9:323-350

Furuya Y (1969) On the fission of troops of Japanese monkeys. II. General view of troop fission of Japanese monkeys. Primates 10: 47-69

Gelman A (2008) Scaling regression inputs by dividing by two standard deviations. Stat Med 27:2865-2873

Gouzoules S (1984) Primate mating systems, kin associations, and cooperative behavior: evidence for kin recognition? Yearb Phys Anthropol 27:99-134

Greenwood PJ (1980) Mating systems, philopatry and dispersal in birds and mammals. Anim Behav 28:1140-1162

Hanson MB, Baird RW, Ford JKB, Hempelmann-Halos J, van Doornik D, Candy JR, Emmons CK, Schorr GS, Gisborne B, Ayres KL, Wasser SK, Balcomb KC, Balcomb-Bartok K, Sneva JG, Ford MJ (2010) Species and stock identification of prey eaten by endangered southern resident killer whales in their summer range. Endanger Species Res 11:69-82

Henzi SP, Lycett JE, Piper SE (1997) Fission and troop size in a mountain baboon population. Anim Behav 53:525-535

Holekamp KE, Smale L (1991) Dominance acquisition during mammalian social development: the "inheritance" of maternal rank. Am Zool 31:306-317

Holekamp KE, Cooper SM, Katona CI, Berry NA, Frank LG, Smale L (1997) Patterns of association among female Spotted Hyenas (Crocuta crocuta). J Mammal 78:55-64

Isbell LA, van Vuren D (1996) Differential costs of locational and social dispersal and their consequences for females group-living primates. Behaviour 133:1-36

Ivkovich T, Filatova OA, Burdin AM, Sato H, Hoyt E (2010) The social organization of resident-type killer whales (Orcinus orca) in Avacha Gulf, Northwest Pacific, as revealed through association patterns and acoustic similarity. Mamm Biol 75:198-210

Johnson CN (1986) Sex-biased philopatry and dispersal in mammals. Oecologia 69:626-627 
Johnstone RA, Cant MA (2010) The evolution of menopause in cetaceans and humans: the role of demography. Proc R Soc Lond B 277:37653771

Kaplan EL, Meier P (1958) Nonparametric estimation from incomplete observations. J Am Stat Assoc 53:457-481

Kastelein RA, Kershaw J, Berghout E, Wiepkema PR (2003) Food consumption and suckling in killer whales Orcinus orca at Marineland Antibes. Int Zool Yearb 38:204-218

Kope R, Parken CK (2011) Recent trends in abundance of chinook salmon stocks from British Columbia, Washington, Oregon, and California. In: Evaluating the Effects of Salmon Fisheries on Southern Resident Killer Whales: Workshop 1, Seattle, pp 1-5

Kriete B (1995) Bioenergetics in the killer whale, Orcinus orca. Dissertation, University of British Columbia

Kudo H, Dunbar RIM (2001) Neocortex size and social network size in primates. Anim Behav 62:711-722

Lawson Handley LJ, Perrin N (2007) Advances in our understanding of mammalian sex-biased dispersal. Mol Ecol 16:1559-1578

Lefebvre D, Ménard N, Pierre JS (2003) Modelling the influence of demographic parameters on group structure in social species with dispersal asymmetry and group fission. Behav Ecol Sociobiol 53: 402-410

Lehmann J, Dunbar RIM (2009) Network cohesion, group size and neocortex size in female-bonded Old World primates. Proc R Soc Lond B 276:4417-4422

Liaw A, Wiener M (2015) Package 'randomForest': Breiman and Cutler's random forests for classification and regression. R package, version 4.6.12, https://cran.r-project.org/web/packages/ randomForest/randomForest.pdf

Lusseau D, Williams R, Wilson B, Grellier K, Barton T, Hammond P, Thompson $P$ (2004) Parallel influence of climate on the behaviour of Pacific killer whales and Atlantic bottlenose dolphins. Ecol Lett 7: 1068-1076

Lutermann H, Schmelting B, Radespiel U, Ehresmann P, Zimmermann B (2006) The role of survival for the evolution of female philopatry in a solitary forager, the grey mouse lemur (Microcebus murinus). Proc R Soc Lond B 273:2527-2533

Majolo B, De Bortoli VA, Shino G (2008) Costs and benefits of group living in primates: group size effects on behaviour and demography. Anim Behav 76:1235-1247

Matkin CO, Ellis G, Olesiuk P, Saulitis E (1999a) Association patterns and inferred genealogies of resident killer whales, Orcinus orca, in Prince William Sounds, Alaska. Fish Bull 97:900-919

Matkin CO, Ellis GM, Saulitis EL, Barrett-Lennard L, Matkin DR (1999b) Killer whales of southern Alaska. North Gulf Oceanic Society, Homer, Alaska

Matkin CO, Barrett-Lennard L, Yurk H, Ellifrit D, Trites A (2007) Ecotypic variation and predatory behavior of killer whales Orcinus orca in the eastern Aleutian Islands, Alaska. Fish Bull 105:74-87

McAuliffe K, Whitehead H (2005) Eusociality, menopause and information in matrilineal whales. Trends Ecol Evol 20:650

McComb K, Moss C, Durant SM, Baker L, Sayialel S (2001) Matriarchs as repositories of social knowledge in African elephants. Science 292:491-494

McComb K, Shannon G, Durant SM, Sayialel K, Slotow R, Poole J, Moss C (2011) Leadership in elephants: the adaptive value of age. Proc R Soc Lond B 278:3270-3276

Melnick DJ, Kidd KK (1983) The genetic consequences of social group fission in a wild population of rhesus monkeys (Macaca mulatta). Behav Ecol Sociobiol 12:229-236

Ménard N, Vallet D (1993) Dynamics of fission in a wild Barbary macaque group (Macaca sylvanus). Int J Primatol 14:479-500

Nash LT (1976) Troop fission in free-ranging baboons in the Gombe Stream National Park, Tanzania. Am J Phys Anthropol 44:63-78

Noren DP (2011) Estimated field metabolic rates and prey requirements of resident killer whales. Mar Mammal Sci 27:60-77
Oi T (1988) Sociological study on the troop fission of wild Japanese monkeys (Macaca fuscata yakui) on Yakushima Island. Primates 29:1-19

Olesiuk PF, Ellis GM, Ford JKB (2005) Life history and population dynamics of northern resident killer whales (Orcinus orca) in British Columbia. DFO Can Sci Advis Sec Res Doc 2005/045, https://waves-vagues.dfo-mpo.gc.ca/Library/324059.pdf

Osborne RW (1999) A historical ecology of Salish Sea "resident" killer whales (Orcinus orca): with implications for management. University of Victoria, Dissertation

Pacific Salmon Commission (1987-2015) Pacific Salmon Commission Joint Chum Technical Committee post season summary reports, 1987-2015. Pacific Salmon Commission, Vancouver, BC http:// www.psc.org/publications_tech_techcommitteereport.htm

Parsons KM, Balcomb KC, Ford JKB, Durban JW (2009) The social dynamics of southern resident killer whales and conservation implications for this endangered population. Anim Behav 77:963-971

Pollack L, Rubenstein DR (2015) The fitness consequences of kin-biased dispersal in a cooperatively breeding bird. Biol Lett 11:20150336

Pollard KA, Blumstein DT (2008) Time allocation and the evolution of group size. Anim Behav 76:1683-1699

R Development Core Team (2015) R: A language and environment for statistical computing. R Foundation for Statistical Computing, Vienna, Austria http://www.R-project.org/

Ren B, Li D, Garber PA, Li M (2012) Fission-fusion behavior in Yunnan snub-nosed monkeys (Rhinopithecus bieti) in Yunnan, China. Int J Primatol 33:1096-1109

Schaffner CM, Rebecchini L, Ramos-Fernandez G, Vick LG, Aureli F (2012) Spider monkeys (Ateles geoffroyi yucatenensis) cope with the negative consequences of hurricanes through changes in diet, activity budget, and fission-fusion dynamics. Int $\mathrm{J}$ Primatol 33: 922-936

Scheel D, Matkin CO, Saulitis E (2001) Distribution of killer whale pods in Prince William Sound, Alaska 1984-1996. Mar Mammal Sci 17: 555-569

Schielzeth H (2010) Simple means to improve the interpretability of regression coefficients. Methods Ecol Evol 1:103-113

Schwarz G (1978) Estimating the dimension of a model. Ann Stat 6:461464

Shultz S, Dunbar RIM (2007) The evolution of the social brain: anthropoid primates contrast with other vertebrates. Proc R Soc Lond B 274:2429-2436

Stredulinsky EH (2016) Determinants of group splitting: an examination of environmental, demographic, genealogical and state-dependent factors of matrilineal fission in a threatened population of fisheating killer whales (Orcinus orca) [Appendix 1]. MSc thesis, University of Victoria

Sueur C, Maire A (2014) Modelling animal group fission using social network dynamics. PLoS ONE 9:e97813

Sueur C, Deneubourg J-L, Petit O, Couzin ID (2011) Group size, grooming and fission in primates: a modeling approach based on group structure. J Theor Biol 273:156-166

Therneau TM (2014) Package 'survival': survival analysis. R package, version 2.37.7, https://cran.r-project.org/web/packages/survival/ survival.pdf

Thierry B, Singh M, Kaumanns W (2004) Macaque societies: a model for the study of social organization. Cambridge University Press, Cambridge

Towers JR, Pilkington JF, Gisborne B, Wright BM, Ellis GM, Ford JKB, Doniol-Valcroze T (2020) Photo-identification catalogue and status of the northern resident killer whale population in 2019. Can Tech Rep Fish Aquat Sci 3371 https://waves-vagues.dfo-mpo.gc.ca/ Library/40877012.pdf

Van Horn RC, Buchan JC, Altmann JC, Altmann J, Alberts SC (2007) Divided destinies: group choice by female savannah baboons during social group fission. Behav Ecol Sociobiol 61:1823-1837 
VanderWaal KL, Mosser A, Packer C (2009) Optimal size, dispersal decisions and post dispersal relationships in female African lions. Anim Behav 77:949-954

Vélez-Espino LA, Ford JKB, Ward E et al (2013) Sensitivity of resident killer whale population dynamics to Chinook salmon abundance. Completion Report, Pacific Salmon Commission, Southern Boundary Restoration and Enhancement Fund, Vancouver

Vélez-Espino LA, Ford JKB, Araujo HA, Ellis G, Parken CK, Sharma R (2014) Relative importance of Chinook salmon abundance on resident killer whale population growth and viability. Aquat Conserv 25:756-780

Wade PR (1998) Calculating limits to the allowable human-caused mortality of cetaceans and pinnipeds. Mar Mammal Sci 14:1-37

Waite JM (1988) Alloparental care in killer whales (Orcinus orca). MSc thesis, University of California, Santa Cruz

Walters JR (1987) Kin recognition in nonhuman primates. In: Fletcher DF, Michener CD (eds) Kin Recognition in Animals. John Wiley, New York, pp 359-393

Ward EJ, Holmes EE, Balcomb KC (2009) Quantifying the effects of prey abundance on killer whale reproduction. J Appl Ecol 46:632640

Whitehead H (2008) Analyzing Animal Societies: quantitative methods for vertebrate social analysis. University of Chicago Press, Chicago

Whitehead H, Weilgart L (2000) The sperm whale: social females and roving males. In: Mann J, Connor RC, Tyack P, Whitehead H (eds) Cetacean societies: field studies of dolphins and whales. University of Chicago Press, Chicago, pp 154-172
Widdig A, Nürnberg P, Bercovitch FB, Trefilov A, Berard JB, Kessler MJ, Schmidtke J, Streich WJ, Krawczak M (2006) Consequences of group fission for the patterns of relatedness among rhesus macaques. Mol Ecol 15:3825-3832

Williams R, Noren DP (2009) Swimming speed, respiration rate and estimated cost of transport in adult killer whales. Mar Mammal Sci 25:327-350

Williams TM, Estes JA, Doak DF, Springer AM (2004) Killer appetites: assessing the role of predators in ecological communities. Ecology 85:3373-3384

Williams R, Krkošek M, Ashe E, Branch TA, Clark S, Hammond PS, Hoyt E, Noren DP, Rosen D, Winship A (2011) Competing conservation objectives for predators and prey: estimating killer whale prey requirements for Chinook salmon. PLoS ONE 6:e26738

Wittemyer G, Douglas-Hamilton I, Getz WM (2005) The socioecology of elephants: analysis of the processes creating multitiered social structures. Anim Behav 69:1357-1371

Wright BM, Stredulinsky EH, Ellis GM, Ford JKB (2016) Kin-directed food sharing promotes lifetime natal philopatry of both sexes in a population of fish-eating killer whales, Orcinus orca. Anim Behav 115:81-95

Zuur AF, Ieno EN, Elphick CS (2010) A protocol for data exploration to avoid common statistical problems. Methods Ecol Evol 1:3-14

Publisher's note Springer Nature remains neutral with regard to jurisdictional claims in published maps and institutional affiliations. 